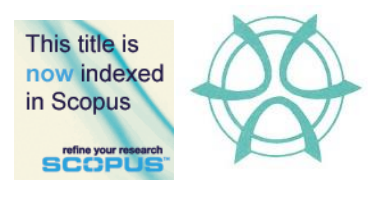

PLANNING MALAYSIA:

Journal of the Malaysian Institute of Planners

VOLUME 15 ISSUE 2 (2017), Page 67 - 74

\title{
RECREATIONAL FACILITIES FOR YOUTH IN MALAYSIAN URBAN AREAS. CASE STUDIES: LEMBAH PANTAI, KUALA LUMPUR AND KOTA KINABALU, SABAH
}

\author{
Dasimah Omar ${ }^{1}$, Kamarul Ariff Omar², Zuriyati Kamaludin ${ }^{3}$, Saberi Othman ${ }^{4}$, \& \\ Zaharah Mohd Yusoff ${ }^{5}$ \\ ${ }^{1,2,3,5}$ Faculty of Architecture, Planning and Surveying, \\ UNIVERSITI TEKNOLOGI MARA (UiTM) \\ ${ }^{4}$ Faculty of Science \\ UNIVERSITI PENDIDIKAN SULTAN IDRIS
}

\begin{abstract}
Recreational facilities refer to places or buildings that provide space for any kind of leisure activities. Recreational activities are often considered to be fun and undertaken mostly by youth for enjoyment, amusement or pleasure. The level of satisfaction is, however, depends on individual's opinion. The purpose of this study is to evaluate the perception level of youth living in urban neighbourhoods towards the recreational facilities provided in their areas. Data from case studies were collected through questionnaire survey involving 540 respondents aged between 15-24 years old. Results of analyses show that respondents were more aware of the availability of recreational facilities related to popular sports. Additionally, mean analysis show that respondents perceived the provision of recreational facilities in their areas as acceptable.
\end{abstract}

Keywords: Recreational facilities, perception, urban area, youth

Date Received: $26^{\text {th }}$ July 2016

Date of Acceptance: $6^{\text {th }}$ July 2017 
Dasimah Omar, Kamarul Ariff Omar, Zuriyati Kamaludin, Saberi Othman, \& Zaharah Mohd Yusoff Recreational Facilities for Youth in Malaysian Urban Areas. Case Studies: Lembah Pantai \& Kota Kinabalu

\section{INTRODUCTION}

The importance of the physical environment to active outdoor recreation is very complex. The socio-ecological theoretical framework indicates that a wide range of features related to the physical environment appears to influence people's active outdoor recreation, which (Sallis, Bauman \& Pratt, 1998). Some studies conclude that changes in the physical environment effectively can change people's behaviour (Marcus \& Forsyth, 1999). A change in the physical environment, however, does not necessarily lead to increase use or activity, and often some kind of intervention or activation of the area and the facilities maybe necessary (Pawlowski, Andersen \& Troelsen, 2016).

The aim of this paper is to determine the perception of youth living in urban areas towards the recreational facilities provided near their neighbourhoods. Youth, which was the target group for this study, refers to the group of person between the age of 15 to 24 years old. At this age, most of them spend much time engaging in recreational activities, including outdoor activities.

Recreation is an activity of leisure. Leisure being discretionary time (Yukic, 1970). The need to do something for recreation is an essential element of human biology and psychology (Daniels, 1995). Meanwhile, Ricketts, JohnsonWebb and Randolph (1998) define urban as comprising all territory, population and housing units in urbanized areas and in places of 2,500 or more persons outside urbanized areas.

This paper mainly focuses on the physical aspects of recreational facilities in urban areas. It refers to the level of the existing provision of recreational facilities which includes adequacy ratio, usage satisfaction, accessibility and maintenance of existing recreational facilities. These factors affect youth decision to visit recreational facilities.

\section{RESEARCH BACKGROUND}

Two case studies were selected for the purpose of this research. Both involved People's Housing Programme, or popularly known in Malaysia as Program Perumahan Rakyat (PPR), that are located in urban areas. The first one was the PPR Kerinchi, in Lembah Pantai, Kuala Lumpur (Figure 1). PPR is a government housing programme to accommodate the housing needs of low-income earners. The National Housing Department of the Ministry of Urban Wellbeing, Housing and Local Government is the implementing agency for PPR projects across the country. PPR Kerinchi is one of the 25 PPRs located in Lembah Pantai. It consists of six 20-storey blocks with a total of 1,896 unit of three bedroom flats.

Based on the number of housing units, the population was estimated in excess of 10,000 people. The population was made up of $49 \%$ Malays, $19 \%$ Chinese and 32\% Indians. Most of the residents were blue-collar workers living in flats that were sold to them under the PPR when they were resettled from their squatter homes. In terms of respondents, 400 youths who live in PPR Kerinchi were selected as respondents to the questionnaire survey (Table 1). 
PLANNING MALAYSIA

Journal of the Malaysia Institute of Planners (2017)

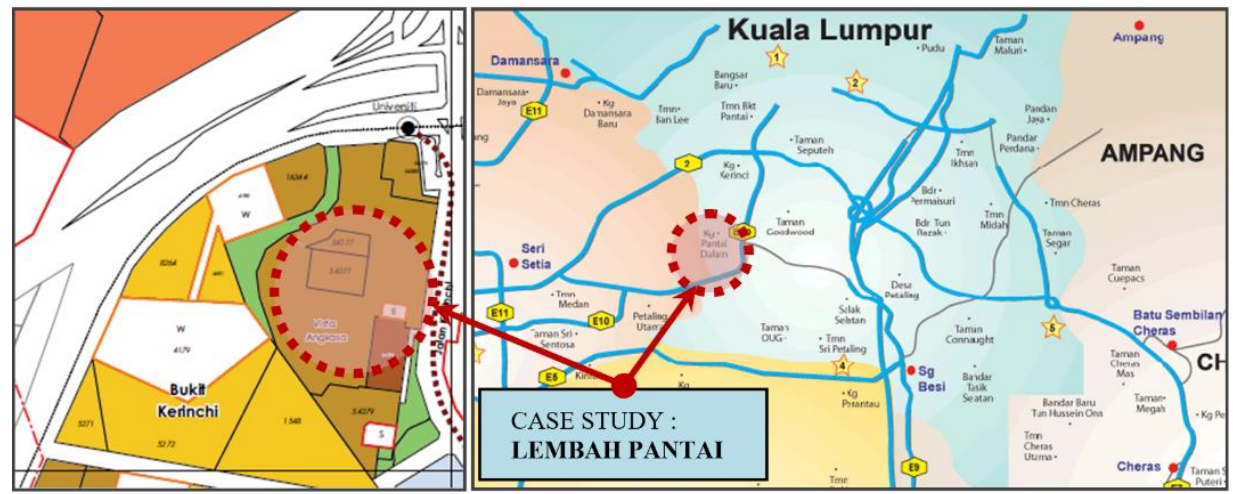

Figure 1 Case Study Area - Lembah Pantai

The second case study was Kota Kinabalu, Sabah (Figure 2). There are only 3 PPRs in Kota Kinabalu, thus the total respondents sampled for the survey was only 140 youths who were living in the PPRs in the area. Sample was selected using snowball sampling technique. Respondents were contacted through youth club leaders in Kota Kinabalu.

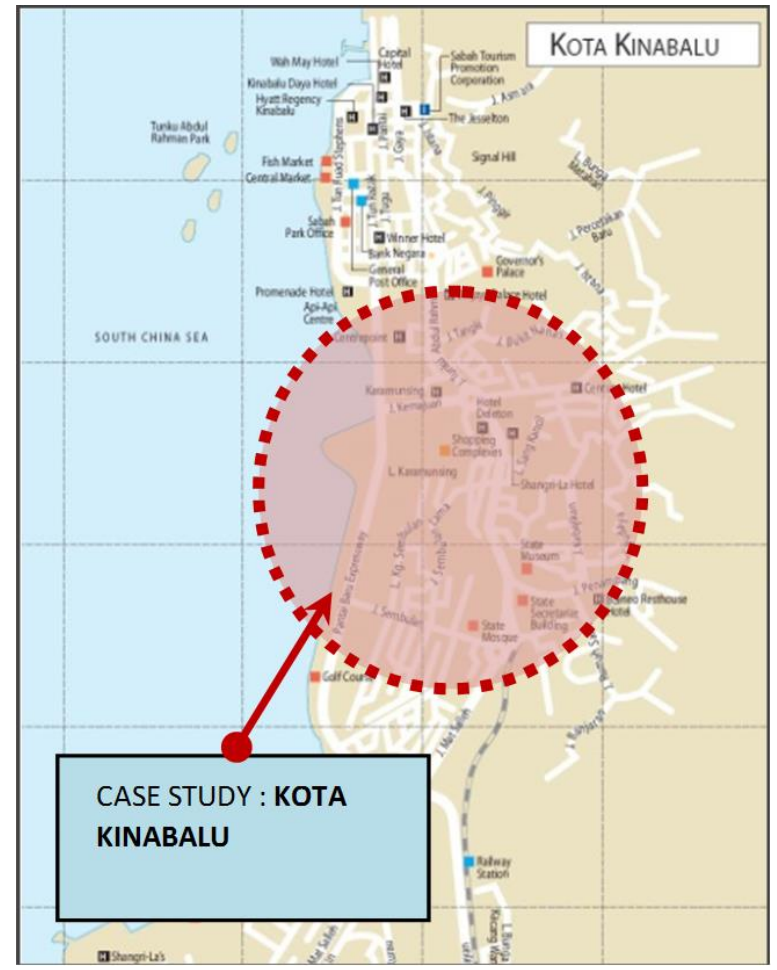

Figure 2 Case Study Area - Kota Kinabalu 
Dasimah Omar, Kamarul Ariff Omar, Zuriyati Kamaludin, Saberi Othman, \& Zaharah Mohd Yusoff Recreational Facilities for Youth in Malaysian Urban Areas. Case Studies: Lembah Pantai \& Kota Kinabalu

For both case studies, the respondents were selected randomly according to several criteria to represent gender, age and ethnicity. They were then surveyed using a set of questionnaire that consisted two sections. Section A recorded the respondents' demographic background while Section B surveyed respondents' perception level on the outdoor recreational facilities provided in their neighbourhood.

Table 1 Number of Respondents by Case Study Area

\begin{tabular}{lcc}
\hline Area & Nos. & $\%$ \\
\hline Lembah Pantai, Kuala Lumpur & 400 & 74.0 \\
Kota Kinabalu & 140 & 26.0 \\
\hline Total & 540 & 100.0 \\
\hline
\end{tabular}

Respondents were asked of their perception on eight types of recreational facilities, which were futsal court, badminton court, basketball court, tennis court, football field, gymnasium and jogging track. Respondents' satisfaction were recorded using 5-point Likert scale, with 1 being least satisfied and 5 being most satisfied.

\section{ANALYSIS AND FINDINGS}

\section{Respondents Background}

The results of the survey show that the highest percentage of respondents, which was 26\% (139 respondents), were from households with income range of RM2,001-RM2,500. Meanwhile, 6\% (32 respondents) of the respondents came from families with household income of RM500 or less, which was also the lowest income range in the questionnaire. 188 respondents were secondary school students, 273 were employed and 79 respondents were unemployed.

\section{Availability and Use of Recreational Facilities}

The results on respondents perception on the availability and use of recreational facilities surrounding their residence are as shown in Table 2 below. In general, the results show that respondents were more aware of the existence of facilities for popular sports such as futsal court, badminton court and football field nearby their residential area. However, most respondents were not aware of the existence of facilities of less popular sports nearby their residential area such as basketball court, tennis court and gymnasium. In Malaysia, futsal has become one of the trending sports among youths, and badminton and football have been receiving much attention in the media and probably two of the most popular sports in the country. Similarly, the facilities for these three types of sports have higher usage among the respondents (Table 2). Additionally, the popularity of these sports have also resulted in more of such facilities being provided. These have helped 
PLANNING MALAYSIA

Journal of the Malaysia Institute of Planners (2017)

to create awareness among the respondents on the existence of such facilities in the area. Basketball, tennis and gymnasium are less popular sports among youths in Malaysia. Thus, facilities for these sports are not widely provided. In the event where such facilities were provided, level of use among respondents was quite low (Table 2).

Table 2 Type and Availability of Recreation Facilities in Urban Areas

\begin{tabular}{lcccc}
\hline $\begin{array}{l}\text { Types of Recreation } \\
\text { Facilities }\end{array}$ & \multicolumn{2}{c}{$\begin{array}{c}\text { Availability of Recreation } \\
\text { Facilities }\end{array}$} & \multicolumn{2}{c}{$\begin{array}{c}\text { The Use of Recreation } \\
\text { Facilities by Respondents }\end{array}$} \\
\cline { 2 - 5 } & Yes & No & Yes & No \\
\hline 1. Futsal Court & $474(88 \%)$ & $66(12 \%)$ & $314(58 \%)$ & $226(42 \%)$ \\
2. Badminton Court & $455(84 \%)$ & $85(16 \%)$ & $271(50 \%)$ & $269(50 \%)$ \\
3. Basketball Court & $34(6 \%)$ & $506(94 \%)$ & $25(5 \%)$ & $515(95 \%)$ \\
4. Tennis Court & $24(4 \%)$ & $516(96 \%)$ & $18(3 \%)$ & $522(97 \%)$ \\
5. Football Field & $479(89 \%)$ & $61(11 \%)$ & $282(52 \%)$ & $258(48 \%)$ \\
6. Gymnasium & $29(5 \%)$ & $511(95 \%)$ & $22(4 \%)$ & $518(96 \%)$ \\
7. Jogging Track & $379(70 \%)$ & $161(30 \%)$ & $253(47 \%)$ & $287(53 \%)$ \\
\hline
\end{tabular}

\section{Respondents Perception on Recreational Facilities}

Mean analyses were conducted to determine respondents' perception on the provision of recreational facilities in urban area. The results are as shown in Table 3 below.

Table 3 Respondents' Perception on the Physical Aspects of Recreational Facilities

\begin{tabular}{|c|c|c|c|c|c|c|c|c|c|c|}
\hline \multirow{2}{*}{$\begin{array}{c}\text { Recreation Facilities } \\
\text { Provided in Urban Areas }\end{array}$} & \multicolumn{2}{|c|}{ Sufficiency } & \multicolumn{2}{|c|}{$\begin{array}{c}\text { Usage } \\
\text { Satisfaction }\end{array}$} & \multicolumn{2}{|c|}{ Distance } & \multicolumn{2}{|c|}{ Accessibility } & \multicolumn{2}{|c|}{ Maintenance } \\
\hline & Mean & Rank & Mean & Rank & Mean & Rank & Mean & Rank & Mean & Rank \\
\hline 1. Futsal Court & 3.62 & 1 & 3.57 & 3 & 3.85 & 2 & 3.85 & 2 & 3.63 & 2 \\
\hline 2. Badminton Court & 3.56 & 3 & 3.58 & 2 & 3.86 & 1 & 3.88 & 1 & 3.69 & 1 \\
\hline 3. Basketball Court & 3.34 & 5 & 3.31 & 6 & 3.46 & 6 & 3.39 & 6 & 3.39 & 5 \\
\hline 4. Tennis Court & 3.33 & 6 & 3.30 & 7 & 3.17 & 7 & 3.30 & 7 & 2.96 & 7 \\
\hline 5. Football Field & 3.31 & 7 & 3.46 & 4 & 3.60 & 4 & 3.71 & 3 & 3.47 & 4 \\
\hline 6. Gymnasium & 3.59 & 2 & 3.43 & 5 & 3.54 & 5 & 3.51 & 5 & 3.39 & 5 \\
\hline 7. Jogging Track & 3.47 & 4 & 3.62 & 1 & 3.68 & 3 & 3.68 & 4 & 3.60 & 3 \\
\hline
\end{tabular}

The results in Table 3 show respondents perceived that futsal court provision is most sufficient (mean 3.62) compared to other recreational facilities. The lowest ranked facilty was football field, with mean 3.31. The popularity of football may have led to high demand for football field, thus making it least sufficient among the facilities surveyed. 
Dasimah Omar, Kamarul Ariff Omar, Zuriyati Kamaludin, Saberi Othman, \& Zaharah Mohd Yusoff Recreational Facilities for Youth in Malaysian Urban Areas. Case Studies: Lembah Pantai \& Kota Kinabalu

In terms of usage satisfaction, the highest ranked facility was jogging track, with mean 3.62. Meanwhile, the lowest ranked was tennis court, with mean 3.31 .

In terms of distance of facilties from residential areas or users, badminton court received the most favourable response from respondents, with mean 3.86 . Similarly, badminton court also ranked first in terms of accessibility and maintenance, with mean 3.88 and 3.69 respectively. This was followed by futsal court, which ranked second in all the three aspects with mean 3.85 for distance, 3.85 for accessibility and 3.63 for maintenance. Meanwhile, tennis court was the lowest ranked facility in all the three aspects. The mean for tennis court distance was 3.17 , for accessibility 3.30 and for maintenance 2.96 .

The results also show that popular sports in Malaysia generally received better perception from the repondents as compared to the less popular sports. In every aspect, bar sufficiency, futsal court, badminton court and football field ranked higher than tennis court, gymnasium and basketball court. This result corroborates the earlier finding where more respondents were aware of the availability of recreational facilities of the popular sports (Table 2).

\section{DISCUSSION}

In overall, respondents' perception of the recreational facilities in urban areas is acceptable. The mean analysis returned a value of greater than 3 for every aspect of every type of recreational facilities, except for tennis court which received mean 2.96 for maintenance aspect. However, none of the recreational facilities received mean value of more than 4 (satisfied) or mean value 5 (most satisfied) in any of the aspects surveyed.

Due to high number of population in urban areas, demand for recreational facilities is also high. In the case of PPR, the population density is higher than many other parts of the urban areas, creating higher demand for recreational facilities. Therefore, it is crucial to ensure that the facilities are sufficiently provided. However, space to locate recreational facilities in urban areas may be scarce, thus hampering efforts to provide sufficient recreational facilities in the area.

While sufficient provision of recreational facilities is crucial, the location of the facilities is also important. Recreational facilities must be located in an area where they are accessible and close to the users, which in this case, the youth. Distance and accessibility are of great importance to users participation in active outdoor recreation. Generally, closer proximity to facilities has a positive impact on participation in active outdoor life (Gobster, 1995). Accessibility, however, is not necessarily consistent with distance and relates to the experience of proximity and access to a special area. Accessibility may be affected by infrastructure, among others, and good accessibility seems to be positively associated with participation in active outdoor recreation (Andkjaer \& Arvidsen, 2015). 
PLANNING MALAYSIA

Journal of the Malaysia Institute of Planners (2017)

In the context of this study, youth from PPR are mostly from lower income households and they do not own personal transportation. Therefore, proximity of recreational facilities to residential areas is very important to allow these youth to easily access the facilities. Additionally, public transport linkage between residential areas and farther recreational facilities is also vital.

Usage of recreational facilities by youth is also affected by their lifestyle. Youth nowadays are often more occupied with their electronic devises such as smartphones, computers and others. This make it even more important that provision of recreational facilities, especially in urban areas, can entice youth to visit and use the facilities. Therefore, provision of such facilities must be well planned. All the important aspects of recreational facilities provision such as numbers, distance, accessibility and maintenance are considered.

\section{CONCLUSION}

This study looks at the perception of youths in PPR on the provision of recreational facilities in their area. It found out that respondents were more aware of the provision of facilities for popular sports. It also found out that, in overall, respondents find the level of provision of recreational facilities in their area as acceptable. It is hoped that these findings would assist the relevant parties such as the local authorities and the sports ministry in planning for improved provision of recreational facilities in urban areas in the future. Such facilities is important in order to create a channel for youths, especially in PPR, to participate in active outdoor lifestyle. This, in turn, would lead to a healthier society, both socially and health-wise.

\section{ACKNOWLEDGEMENTS}

This research paper is made possible by the Long Term Research Grant Scheme (LRGS 2014-0006-106-42), Universiti Pendidikan Sultan Idris Perak associated with Universiti Teknologi MARA Shah Alam, Universiti Putra Malaysia and Universiti Malaysia Kelantan. Special thanks to the supportive respondents and friends in supporting the success of this research paper.

\section{REFERENCES}

Andkjaer, S., \& Arvidsen, J. (2015). Places for active outdoor recreation - a scoping review. Journal of Outdoor Recreation and Tourism, 12, 25-46.

Daniels, B. C. (1995). Puritans at play. Leisure and recreation in colonial New England. New York: St. Martin's Press.

Dasimah Omar, Kamarul Ariff Omar, Saberi Othman, \& Zaharah Mohd Yusoff (2016, April). Walkability design for urban public housing park. 7th Asian Conference on Environment-Behaviour Studies, Taipei, Taiwan ROC. 
Dasimah Omar, Kamarul Ariff Omar, Zuriyati Kamaludin, Saberi Othman, \& Zaharah Mohd Yusoff

Recreational Facilities for Youth in Malaysian Urban Areas. Case Studies: Lembah Pantai \& Kota Kinabalu

Dasimah Omar, Kamarul Ariff Omar, Saberi Othman, \& Zaharah Mohd Yusoff (2016, February). Youth participation in urban neighbourhood community. AMER International Conference on Quality of Life, Medan, Indonesia.

Gobster, P. H. (1995). Perception and use of a metropolitan green way system for recreation. Landscape and Urban Planning, 33, 401-413.

Marcus, B. H., \& Forsyth, L. H. (1999). How are we doing with physical activity? American Journal of Health Promotion, 14, 118-124.

Pawlowski, C. S., Andersen, H. B., \& Troelsen, J. (2016). Children's physical activity behavior during school recess: a pilot study using GPS, accelerometer, participant observation, and go-along interview. PLoS One, 11(2). doi: 10.1371/journal.pone.0148786.

Ricketts, T. C., Johnson-Webb, K. D., \& Randolph, R. K. (1999). Populations and places in rural America. In Ricketts, T. C. (Ed.). Rural health in the United States (pp. 7-24). Oxford University Press.

Sallis, J. F., Bauman, A., \& Pratt, M. (1998). Environmental and policy interventions to promote physical activity. American Journal of Preventive Medicine, 15(4), 379-397.

Yukic, T. S. (1970). Fundamentals of recreation (2nd edition). Joanna Cotler Books. 